\title{
A comparison of oral controlled-release morphine and oxycodone with transdermal formulations of buprenorphine and fentanyl in the treatment of severe pain in cancer patients
}

\author{
This article was published in the following Dove Press journal: \\ Drug Design, Development and Therapy \\ 22 August 2017 \\ Number of times this article has been viewed
}

\section{Krzysztof Nosek' \\ Wojciech Leppert ${ }^{2,3}$ \\ Hanna Nosek ${ }^{4}$ \\ Jerzy Wordliczek ${ }^{5}$ \\ Dariusz Onichimowski ${ }^{6}$}

'Non-public Saint Lazarius Health Care Unit, Biskupiec, ${ }^{2}$ Chair and Department of Palliative Medicine, Poznan University of Medical Sciences, Poznań, ${ }^{3}$ Department of Quality of life Research, Gdańsk Medical University, Gdańsk, ${ }^{4}$ Department of Paediatrics, Regional Children Specialized Hospital, Olsztyn, ${ }^{5}$ Department of Interdisciplinary Intensive Care, Jagiellonian University College of Medicine, Kraków, ${ }^{6}$ Department of Intensive Care, Regional Hospital, Olsztyn, Poland
Correspondence: Wojciech Leppert Chair and Department of Palliative Medicine, Poznan University of Medical Sciences, Osiedle Rusa 55, 6I-245 Poznań, Poland

Tel/fax +48 6I 8738303

Email wojciechleppert@wp.pl
Aim of the study: To compare analgesia and adverse effects during oral morphine and oxycodone and transdermal fentanyl and buprenorphine administration in cancer patients with pain.

Patients and methods: Cancer patients treated at home and in outpatient clinics with severe pain (numerical rating scale score 6-10) fail to respond to non-opioids and/or weak opioids. All patients were randomized to either morphine, oxycodone, fentanyl or buprenorphine and divided into subgroups with predominant neuropathic and nociceptive pain component. Doses of opioids were titrated to satisfactory analgesia and acceptable adverse effects intensity. Patients were assessed at baseline and followed for 28 days. In all patient groups, immediate-release oral morphine was the rescue analgesic and lactulose $10 \mathrm{~mL}$ twice daily was the prophylaxis of constipation; no antiemetics were used as prophylaxis.

Results: A total of 62 patients participated and 53 patients completed the study. Good analgesia was obtained for all 4 opioids, for both nociceptive and neuropathic pain. The use of co-analgesics was greater in patients with neuropathic pain. Morphine treatment was associated with less negative impact of pain on ability to walk, work and activity (trend) according to Brief Pain Inventory-Short Form scores and less consumption of rescue morphine. The most common adverse effects included nausea and drowsiness, which increased at the beginning of the treatment and gradually decreased over the days to come. Appetite, well-being, anxiety, depression, and fatigue improved. There was no constipation (the Bowel Function Index scores were within normal range) during the treatment with all opioids. No changes were seen for constipation, vomiting and dyspnea.

Conclusion: All opioids were effective and well-tolerated. Morphine was the most effective in the improvement in some of the Brief Pain Inventory-Short Form items regarding negative impact of pain on patients' daily activities. Prophylaxis of constipation was effective; antiemetics may be considered for nausea prevention.

Keywords: adverse effects, analgesia, opioid analgesics, treatment

\section{Introduction}

In 1986, World Health Organization (WHO) experts developed the principles of pain treatment in cancer patients based on pharmacological (3-step analgesic ladder) and non-pharmacological management, which comprises oncological palliative treatment, mainly radiotherapy, intervention techniques of pain treatment: peripheral and central blocks, neurolytic blocks, termolesion, kriolesion and neurosurgical procedures. ${ }^{1}$ 
Pharmacotherapy involves using non-opioid analgesics, opioids and co-analgesics (analgesic adjuvants). The most frequently recommended route of analgesics administration is the oral route, which is usually effective and convenient for the patients. ${ }^{2,3}$ In the recent years, thanks to the availability of opioids administered transdermally, the transdermal route is the one which is recognized as equally convenient or even more convenient than oral route and at the same time recommended in those patients who cannot receive drugs by oral route. In pain syndromes that are difficult to treat, the administration of analgesics and adjuvant analgesics intravenously and intrathecally may occasionally produce good effects. ${ }^{4}$ According to European Association for Palliative Care (EAPC) and European Society for Medican Oncology (ESMO) guidelines, morphine and oxycodone administered orally are first-line opioids used to treat moderate-to-severe pain, while fentanyl and buprenorphine are alternatives used in cancer patients with stable pain syndromes, especially when oral administration of opioids is not possible. ${ }^{5,6}$ Few studies compared analgesic efficacy and adverse effects of morphine, oxycodone (both administered by an oral route), fentanyl and buprenorphine (both administered by the transdermal route). Corli et al compared all 4 opioids in an explanatory analysis conducted in cancer patients, which revealed similar efficacy of all opioids studied. ${ }^{7}$ All 4 opioids were then compared in a randomized study, which demonstrated similar analgesic efficacy and adverse effects profile of patients treated with the drugs studied. ${ }^{8}$ However, patients' quality of life (QoL) was not evaluated in this study.

The aim of the study was to compare analgesic effect of morphine and oxycodone administered by oral route, as well as fentanyl and buprenorphine administered transdermally in cancer patients with severe pain and the comparison of adverse effects of the opioids was studied, including their effects on the gastrointestinal functions.

\section{Patients and methods}

The trial enrolled patients $>18$ years old who provided written informed consent to participate in the clinical trial, were treated in the Home Hospice or Palliative Care Outpatient Clinic and diagnosed with cancer and experienced severe pain (numerical rating scale [NRS] score 6-10), failed to respond to step 1 WHO analgesic ladder drugs and/or weak opioids such as tramadol, codeine, dihydrocodeine. The enrollment criteria included patients who did not present with cognitive disorders as assessed by Mini-Mental State Examination (MMSE), with expected survival time of at least 40 days, without renal or liver dysfunction. The trial did not enroll patients who had previously been treated with strong opioids, those with the symptoms of respiratory insufficiency, disorders of consciousness, central nervous system primary neoplasm or brain metastases, patients who could not receive medications by oral/transdermal route, those with clinically significant liver dysfunction (bilirubin or transaminase level twice exceeding the norm) and/or renal dysfunction (creatinine level above the norm or estimated glomerular filtration rate $[$ eGFR] $<60$ ) and patients undergoing chemotherapy. The trial enrolled 62 patients, of whom 32 were women and 30 men. The group of patients with predominantly neuropathic pain comprised 30 patients ( 15 women and 15 men), while the group with predominantly nociceptive pain included 32 patients (18 women and 14 men). The number of patients in particular groups is shown in Figure 1.

Table 1 presents basic demographic data and comparison of patients' age in particular patient groups.

Different locations of the primary tumor focus were diagnosed in 62 patients participating in the trial. The most common were located in the gastrointestinal system 15 (24.19\%): colon 10 (16.13\%), stomach 3 (4.84\%), esophagus 1 (1.61\%) and pancreas $1(1.61 \%)$. Lung cancer was diagnosed in $14(22.58 \%)$, breast in $8(12.90 \%)$ and prostate in $7(11.29 \%)$ patients. Tumors of urinary system were found in $6(9.68 \%)$ patients, including urinary bladder in $3(4.84 \%)$ and kidney in $3(4.84 \%)$ patients; uterus in $4(6.45 \%)$ patients, including body $3(4.84 \%)$ and cervix 1 (1.61\%) patient. Other locations (isolated cases): ovary, palatine tonsil, larynx, thyroid gland, tongue, skin, carcinoid, primary location unknown were diagnosed in $8(12.90 \%)$ patients.

The patients participating in the trial experienced various types of pain: visceral, bone, neuropathic and superficial somatic pain. In the group of 17 patients treated with buprenorphine, 1 type of pain was found in 3 patients, 2 or more types of pain in 14 patients; in the group of 16 patients treated with oxycodone, 1 type of pain was found in 4 patients, 2 or more types of pain in 12 patients; in the group of

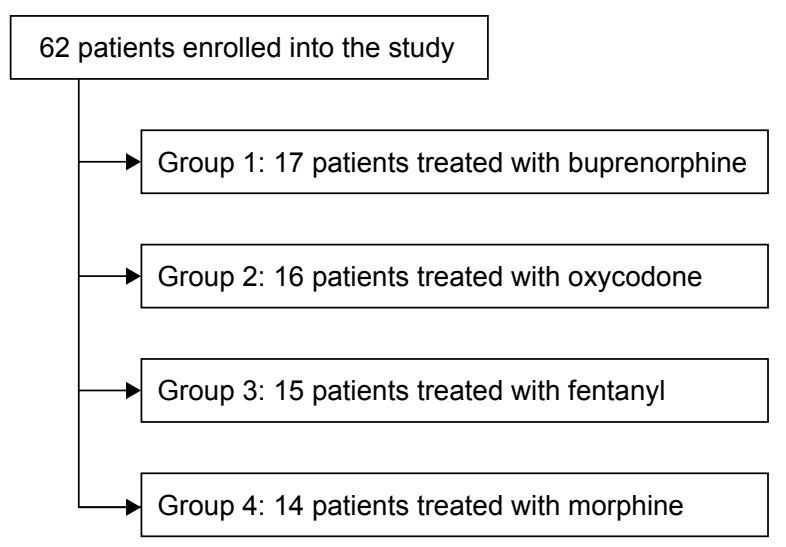

Figure I The number of patients in particular patient groups. 
Table I Basic demographic data of the patients participating in the trial

\begin{tabular}{|c|c|c|c|}
\hline $\begin{array}{l}\text { Patient } \\
\text { group }\end{array}$ & $\begin{array}{l}\text { Age } \\
\text { (years) }\end{array}$ & ANOVA & Sex \\
\hline $\begin{array}{l}\text { Buprenorphine } \\
\text { therapy, } \mathrm{n}=17\end{array}$ & $70.0 \pm 13.4$ & $\begin{array}{l}F(909.3)=1.858 \\
P=0.147\end{array}$ & $\begin{array}{l}\text { Men, } n=10 \\
58.82 \% \\
\text { Women, } n=7 \\
41.18 \%\end{array}$ \\
\hline $\begin{array}{l}\text { Oxycodone } \\
\text { therapy, } n=16\end{array}$ & $72.3 \pm 13.2$ & & $\begin{array}{l}\text { Men, } n=7 \\
43.75 \% \\
\text { Women, } n=9 \\
56.25 \%\end{array}$ \\
\hline $\begin{array}{l}\text { Fentanyl } \\
\text { therapy, } n=15\end{array}$ & $70.7 \pm 10.9$ & & $\begin{array}{l}\text { Men, } n=6 \\
40 \% \\
\text { Women, } n=9 \\
60 \%\end{array}$ \\
\hline $\begin{array}{l}\text { Morphine } \\
\text { therapy, } n=14\end{array}$ & $62.0 \pm 13.4$ & & $\begin{array}{l}\text { Men, } n=6 \\
42.86 \% \\
\text { Women, } n=8 \\
57.14 \%\end{array}$ \\
\hline $\begin{array}{l}\text { Patients with } \\
\text { neuropathic } \\
\text { pain, } n=30\end{array}$ & $71.0 \pm 12.6$ & $\begin{array}{l}F(236.1)=I .398 \\
P=0.242\end{array}$ & $\begin{array}{l}\text { Men, } n=15 \\
50 \% \\
\text { Women, } n=15 \\
50 \%\end{array}$ \\
\hline $\begin{array}{l}\text { Patients with } \\
\text { nociceptive } \\
\text { pain, } n=32\end{array}$ & $67.1 \pm 13.4$ & & $\begin{array}{l}\text { Men, } n=14 \\
43.75 \% \\
\text { Women, } n=18 \\
56.25 \%\end{array}$ \\
\hline $\begin{array}{l}\text { Total number, } \\
\mathrm{n}=62\end{array}$ & $69.0 \pm 13.0$ & & $\begin{array}{l}\text { Men, } n=29 \\
46.77 \% \\
\text { Women, } n=33 \\
53.23 \%\end{array}$ \\
\hline
\end{tabular}

Notes: Age data presented as mean \pm standard deviation. F: Fisher test. Chi-square test; $\chi^{2}=1.431 ; \mathrm{df}=3 ; P=0.703$.

Abbreviation: ANOVA, analysis of variance.

15 patients treated with fentanyl, 1 type of pain was found in 6 patients, 2 or more types of pain in 9 patients; in the group of 14 patients treated with morphine, 1 type of pain was found in 4 patients, 2 or more types of pain in 10 patients. The incidence of occurrence of particular types of pain is shown in Table 2.

\section{Methods}

The trial protocol and the informed consent form were approved by the Bioethical Committee at the University

Table 2 The incidence of occurrence of particular types of pain (number of patients)

\begin{tabular}{lllll}
\hline \multirow{2}{*}{ Type of pain } & \multicolumn{4}{l}{ Opioid treatment } \\
\cline { 2 - 5 } & Buprenorphine & Oxycodone & Fentanyl & Morphine \\
\hline Visceral & II & 10 & 8 & $1 \mathrm{I}$ \\
Bone & II & 10 & 8 & 8 \\
Neuropathic & 7 & 8 & 7 & 8 \\
Superficial & 5 & 2 & 1 & 0 \\
somatic & & & & \\
\hline
\end{tabular}

of Warmia and Mazury in Olsztyn by 257/13 resolution of June 10, 2013, No 257/2013. The trial was conducted from September 2013 to December 2015, in the following centers:

1. St Lazarus Non-public Palliative Care Centre in Biskupiec.

2. MEL-MED Non-public Health Care Centre, Home Hospice in Kościan.

3. Puls-Med Non-public Health Care Centre, Palliative Outpatient Clinic, Home Hospice in Rybnik.

4. Fr Eugeniusz Dutkiewicz Hospice in Gdańsk.

5. Non-public Palliative Health Care Centre in Kalisz.

All patients meeting the trial enrollment criteria were randomized to one of the 4 groups of patients treated with buprenorphine, oxycodone, fentanyl or morphine, respectively. In all patient groups, the rescue opioid used for the treatment of breakthrough pain episodes was immediaterelease morphine administered by an oral route, titrated to satisfactory analgesic effect. The duration of the trial was 28 days. The patients receiving each opioid were further divided into 2 subgroups: patients with predominant nociceptive pain component (bone and/or visceral), and those with predominant neuropathic pain component.

The patients could take adjuvant analgesics in bone pain and neuropathic pain. To prevent constipation, all patients received lactulose in doses of $10 \mathrm{~mL}$ administered twice daily; no antiemetics were used as prophylaxis. The initial doses of the opioids studied were increased to obtain effective analgesia (NRS pain intensity $\leq 4$ ) and acceptable severity of adverse effects according to the following regimen:

1. Controlled-release morphine administered orally every $12 \mathrm{~h}: 2 \times 10,2 \times 20,2 \times 30,2 \times 40,2 \times 60,2 \times 90,2 \times 120,2 \times 150$, $2 \times 180,2 \times 200 \mathrm{mg}$.

2. Controlled-release oxycodone administered orally every $12 \mathrm{~h}: 2 \times 5,2 \times 10,2 \times 15,2 \times 20,2 \times 30,2 \times 45,2 \times 60,2 \times 80$, $2 \times 100,2 \times 120 \mathrm{mg}$.

3. Fentanyl administered by transdermal route every 48-72 h: 25, 37.5, 50, 75, 100, 125, and $150 \mu \mathrm{g} / \mathrm{h}$.

4. Transdermal buprenorphine administered every $60-84 \mathrm{~h}$ : $35,52.5,70,105,140,175$, and $210 \mu \mathrm{g} / \mathrm{h}$.

In this trial, the following research tools were used: MMSE to assess cognitive functions, ${ }^{9}$ Brief Pain InventoryShort Form (BPI-SF) to assess pain intensity and its effect on patients' daily activities, ${ }^{10}$ Edmonton Symptom Assessment System (ESAS) to assess pain, adverse effects and the QoL, ${ }^{11}$ European Organization for Research and Treatment of Cancer QoL Questionnaire Core-15-Palliative Care (EORTC QLQ-C15-PAL) in order to assess QoL, ${ }^{12}$ the Bowel Function 
Index (BFI) to assess bowel movements, ${ }^{13,14}$ Hospital Anxiety and Depression Scale (HADS) to assess the emotional state $^{15,16}$ and the Karnofsky scale to assess patients' performance status (PS). ${ }^{17,18}$

On day 1 of the trial, patients' cognitive functions were assessed using MMSE, and on day 1 and day 28 of the trial, patients' emotional state was assessed by means of HADS. On days 1, 7, 14, 21 and 28 of the trial, the QoL was assessed by means of EORTC QLQ-C15-PAL, patients' PS by means of the Karnofsky scale, and bowel movements by means of BFI. On days 1, 3, 6, 9, 13, 16, 19, 22, 25 and 28 of the trial, the patients completed BPI-SF and ESAS.

\section{Statistical methods}

Statistica data analysis software system, version 12; StatSoft, Inc. 2014 (TIBCO Software Inc., Palo Alto, CA, USA) was used for statistical analysis. The results were presented as arithmetic mean and standard deviation values, minimum and maximum values. In order to compare the age of the patients assigned to particular groups, analysis of variance (ANOVA), and to compare sex of patients, the chi-square test was used. As the data have normal distribution confirmed by the Shapiro-Wilk test, and a condition of homogeneity of variance was confirmed by the Levene test, a 2-factor ANOVA with repeated measurements was used to analyze scores of BPI-SF, ESAS and BFI. There were 2 major effects studied: the effect of the type of treatment (buprenorphine, oxycodone, fentanyl and morphine), the effect of time of treatment and the interactions of the type and duration of therapy. The threshold of $P<0.05$ was adopted as significant.

\section{Results}

Over the period of 28 months, in 5 centers altogether, 62 patients were enrolled in the trial, of whom 53 patients managed to complete the treatment. No signs of dementia were found in the patients studied: MMSE score was within the norm and averaged 28.68 in all patients, 28.72 in the group of patients with neuropathic pain and 28.64 in the group of patients with nociceptive pain. In this article, we report results of pain treatment according to BPI-SF and adverse effects according to ESAS of opioids studied.

A separate report of QoL results based on a full analysis of ESAS, EORTC QLQ-C15-PAL, HADS and Karnofsky will be presented elsewhere.

\section{Analgesic effects}

According to the trial protocol, the intensity of pain was assessed in all patients at baseline and on chosen days of the therapy with the opioids studied, using BPI-SF, ESAS and EORTC QLQ-C15-PAL. Beneficial effects of the analgesic treatment were obtained for all the 4 opioids studied in all patients, in those with predominant neuropathic pain and in patients with predominant nociceptive pain. The greatest reduction in the initial intensity of pain was observed during the first 14 days of the trial.

\section{Brief Pain Inventory-Short Form}

\section{Pain intensity}

The intensity of pain according to BPI-SF: pain at its worst, pain at its least, pain on the average and pain right now experienced at the assessment is presented in Table 3. There was a significant reduction in the initial pain intensity in all pain intensity items.

The results of the 2-factor ANOVA, where the dependent variables were pain BPI-SF intensity scales, and the independent variables were the type of treatment (buprenorphine, oxycodone, fentanyl, morphine) and the time of the therapy (days 1, 7, 14, 21 and 28 of the treatment) are shown in Table 4.

Table 3 Brief Pain Inventory-Short Form (BPI-SF) descriptive statistics, items 3-6

\begin{tabular}{|c|c|c|c|c|c|c|c|c|c|c|}
\hline BPI-SF items & Day I & Day 3 & Day 6 & Day 9 & Day 13 & Day 16 & Day 19 & Day 22 & Day 25 & Day 28 \\
\hline \multirow[t]{2}{*}{ Pain at its worst (3) } & $7.8 I \pm 0.94$ & $6.32 \pm 1.61$ & $5.18 \pm 1.90$ & $4.64 \pm 2.00$ & $4.34 \pm I .77$ & $3.63 \pm 1.46$ & $3.72 \pm 1.99$ & $3.13 \pm 1.56$ & $2.94 \pm 1.43$ & $2.62 \pm 1.21$ \\
\hline & $6-10$ & $2-10$ & $0-8$ & $0-9$ & $1-9$ & $\mathrm{I}-8$ & $1-10$ & $1-9$ & $1-9$ & $1-6$ \\
\hline \multirow[t]{2}{*}{ Pain at its least (4) } & $5.34 \pm 1.80$ & $4.10 \pm 2.01$ & $3.27 \pm 1.91$ & $2.64 \pm 1.82$ & $2.29 \pm 1.56$ & $1.67 \pm 1.39$ & $1.55 \pm 1.46$ & $1.13 \pm 1.35$ & $0.96 \pm 1.04$ & $0.70 \pm 0.90$ \\
\hline & $0-7$ & $0-7$ & $0-6$ & $0-7$ & $0-6$ & $0-5$ & $0-6$ & $0-5$ & $0-4$ & $0-3$ \\
\hline \multirow[t]{2}{*}{ Pain on the average (5) } & $6.77 \pm 1.03$ & $5.27 \pm 1.68$ & $4.32 \pm 1.98$ & $3.49 \pm 1.89$ & $3.13 \pm 1.82$ & $2.65 \pm 1.39$ & $2.57 \pm 1.85$ & $2.08 \pm I .4 \mid$ & $1.87 \pm 1.27$ & $1.57 \pm 0.91$ \\
\hline & $3-9$ & $1-8$ & $0-8$ & $0-7$ & $0-9$ & $0-7$ & $0-8$ & $0-7$ & $0-7$ & $0-4$ \\
\hline \multirow[t]{2}{*}{ Pain right now (6) } & $6.69 \pm 1.22$ & $5.06 \pm 1.84$ & $4.08 \pm 2.03$ & $3.44 \pm 2.12$ & $3.04 \pm 1.87$ & $2.54 \pm 1.49$ & $2.40 \pm 1.95$ & $1.92 \pm 1.70$ & $1.85 \pm 1.34$ & $1.57 \pm 1.07$ \\
\hline & $1-9$ & $0-8$ & $0-8$ & $0-9$ & $0-9$ & $0-7$ & $0-10$ & $0-9$ & $0-7$ & $0-4$ \\
\hline
\end{tabular}

Notes: Mean values, standard deviations, minimum and maximum values are given. The scores are in II-point scale (range 0-10), with a lower score corresponding to a smaller intensity of pain. 
Table 4 The results of the Brief Pain Inventory-Short Form twofactor analysis of variance

\begin{tabular}{|c|c|c|c|}
\hline Item & Main effects & $\boldsymbol{F}$ & $P$-value \\
\hline \multirow[t]{3}{*}{ Pain at its worst (3) } & I & 1.326 (3) & 0.276 \\
\hline & 2 & $108.950(9)$ & $<0.001$ \\
\hline & 3 & $2.559(27)$ & $<0.001$ \\
\hline \multirow[t]{3}{*}{ Pain at its least (4) } & I & $1.140(3)$ & 0.342 \\
\hline & 2 & $102.076(9)$ & $<\mathbf{0 . 0 0 1}$ \\
\hline & 3 & $\mathrm{I} .575$ (27) & 0.035 \\
\hline \multirow[t]{3}{*}{ Pain on the average (5) } & I & $0.687(3)$ & 0.564 \\
\hline & 2 & $130.044(9)$ & $<0.001$ \\
\hline & 3 & $2.733(27)$ & $<0.001$ \\
\hline \multirow[t]{3}{*}{ Pain right now (6) } & I & $0.944(3)$ & 0.427 \\
\hline & 2 & $99.985(9)$ & $<0.001$ \\
\hline & 3 & $2.326(27)$ & $<0.001$ \\
\hline
\end{tabular}

Notes: $F$ : Fisher test, the degrees of freedom are given in parentheses. $P$, significance level. Main effects: I, the drug effect; 2 , time effect; 3 , interactions of I and 2. Item: the numbers in parentheses indicate item number in the questionnaire. Significant values are marked in bold.

In all items of the BPI-SF (pain at its worst, pain at its least, pain on the average, pain right now) pain intensity decreased significantly in the course of the treatment with no differences between all 4 opioids. A highly significant time effect and interactions of treatment time and type of opioid therapy were noted in all items of pain intensity.

\section{The effect of pain on chosen dimensions of patients'} lives

The effect of pain on particular dimensions of life: general activity, mood, the ability to walk, normal work (at home and outside the home), relations with other people, sleep and enjoyment of life, as assessed by means of BPI-SF questionnaire, are presented in Table 5.
Table 6 presents the results of the 2-factor ANOVA, where the dependent variables are the effects of pain on particular dimensions of patients' life in BPI-SF, and independent variables the kind of therapy (buprenorphine, oxycodone, fentanyl and morphine) and the time of treatment (days 7, 14, 21 and 28 of therapy).

\section{The effect of pain on general activity}

Considering the effect of pain on general activity of patients, a slightly better but insignificant effect of morphine, when compared with other opioids, is of note $(P=0.067)$. The effect of pain on general activity of patients in relation to the duration of therapy was significant $(P<0.001)$.

\section{The effect of pain on mood}

The reduction in negative effect of pain on patients' mood was associated with time of the treatment $(P<0.001)$ with no difference between opioids studied. The effect was observed mainly during the first 14 days of the trial.

\section{The effect of pain on the ability to walk}

Considering the effect of pain on patients' ability to walk, significant effects of the type and time of treatment $(P<0.001)$ were observed. Out of the opioids studied, the best effects were obtained during morphine therapy $(P=0.021)$.

\section{The effect of pain on normal work}

In terms of the effect of pain on normal work, significant differences occurred with regard to all the 3 effects studied.

Table 5 Descriptive statistics for items 9A-9G Brief Pain Inventory-Short Form (BPI-SF) concerning the effect of pain on particular dimensions of patients' life

\begin{tabular}{|c|c|c|c|c|c|c|c|c|c|c|}
\hline $\begin{array}{l}\text { BPI-SF } \\
\text { items }\end{array}$ & Day I & Day 3 & Day 6 & Day 9 & Day 13 & Day 16 & Day 19 & Day 22 & Day 25 & Day 28 \\
\hline \multirow[t]{2}{*}{$9 A$} & $6.47 \pm 1.77$ & $5.69 \pm 1.90$ & $4.95 \pm 2.00$ & $4.43 \pm 1.86$ & $3.89 \pm 1.98$ & $3.46 \pm 1.86$ & $3.60 \pm 2.097$ & $3.26 \pm 2.02$ & $3.13 \pm 1.98$ & $2.87 \pm 1.86$ \\
\hline & $2-10$ & $2-10$ & $0-10$ & $0-8$ & $0-9$ & $0-8$ & $0-9$ & $1-9$ & $0-9$ & $0-9$ \\
\hline \multirow[t]{2}{*}{$9 B$} & $5.37 \pm 2.28$ & $4.76 \pm 2.21$ & $4.3 \mathrm{I} \pm 2.29$ & $3.79 \pm 2.12$ & $3.59 \pm 2.27$ & $3.15 \pm 1.91$ & $3.32 \pm 2.06$ & $3.04 \pm 1.81$ & $2.89 \pm 1.95$ & $2.72 \pm 2.02$ \\
\hline & $0-10$ & $0-8$ & $0-8$ & $0-8$ & $0-10$ & $0-8$ & $0-9$ & $0-8$ & $0-8$ & $0-9$ \\
\hline \multirow[t]{2}{*}{$9 \mathrm{C}$} & $5.85 \pm 2.60$ & $5.3 I \pm 2.7 \mid$ & $4.77 \pm 2.79$ & $4.36 \pm 2.66$ & $4.20 \pm 2.88$ & $3.74 \pm 2.80$ & $3.70 \pm 2.91$ & $3.36 \pm 2.82$ & $3.21 \pm 2.87$ & $3.13 \pm 3.01$ \\
\hline & $0-10$ & $0-10$ & $0-10$ & $0-10$ & $0-10$ & $0-10$ & $0-10$ & $0-10$ & $0-10$ & $0-10$ \\
\hline \multirow[t]{2}{*}{$9 D$} & $6.42 \pm 2.4 \mathrm{I}$ & $5.6 \mathrm{I} \pm 2.56$ & $5.13 \pm 2.65$ & $4.66 \pm 2.54$ & $4.4 I \pm 2.67$ & $4.06 \pm 2.72$ & $3.98 \pm 2.59$ & $3.5 I \pm 2.55$ & $3.43 \pm 2.71$ & $3.26 \pm 2.86$ \\
\hline & $1-10$ & $0-10$ & $0-10$ & $0-10$ & $0-10$ & $0-10$ & $0-10$ & $0-10$ & $0-10$ & $0-10$ \\
\hline \multirow[t]{2}{*}{$9 \mathrm{E}$} & $4.95 \pm 2.00$ & $4.37 \pm 1.88$ & $3.90 \pm 2.01$ & $3.36 \pm 1.64$ & $3.39 \pm 1.96$ & $2.70 \pm 1.55$ & $2.85 \pm 1.93$ & $2.53 \pm 1.81$ & $2.15 \pm 1.68$ & $1.92 \pm 1.52$ \\
\hline & $0-10$ & $0-8$ & $0-9$ & $0-8$ & $0-10$ & $0-7$ & $0-9$ & $0-9$ & $0-8$ & $0-5$ \\
\hline \multirow[t]{2}{*}{$9 \mathrm{~F}$} & $4 .|3 \pm 2.4|$ & $3.65 \pm 2.31$ & $3.29 \pm 2.08$ & $2.95 \pm 2.11$ & $3.00 \pm 2.16$ & $2.48 \pm 1.76$ & $2.47 \pm 2.01$ & $2.23 \pm 2.06$ & $2.04 \pm 1.69$ & $2.00 \pm 1.69$ \\
\hline & $0-9$ & $0-10$ & $0-8$ & $0-9$ & $0-9$ & $0-7$ & $0-10$ & $0-10$ & $0-6$ & $0-6$ \\
\hline \multirow[t]{2}{*}{$9 \mathrm{G}$} & $5.34 \pm 2.22$ & $4.65 \pm 2.21$ & $4.13 \pm 2.26$ & $3.74 \pm 2.10$ & $3.55 \pm 2.04$ & $3.04 \pm 1.80$ & $3.06 \pm 1.91$ & $2.77 \pm 1.96$ & $2.57 \pm 1.85$ & $2.32 \pm 1.76$ \\
\hline & $0-10$ & $0-10$ & $0-9$ & $0-9$ & $0-8$ & $0-7$ & $0-8$ & $0-9$ & $0-9$ & $0-8$ \\
\hline
\end{tabular}

Notes: 9A, general activity; 9B, mood; 9C, ability to walk; 9D, normal work (at home and outside the home); 9E, relations with other people; 9F, sleep; 9G, enjoyment of life. There are mean values, followed by standard deviations, minimum and maximum values. The scores are given in II-point scale (range 0-10). A lower score denotes a smaller negative effect of pain on particular dimensions of patients' life. 
Table 6 The results of Brief Pain Inventory-Short Form twofactor analysis of variance for items $9 A-9 G$

\begin{tabular}{|c|c|c|c|}
\hline Pain interference with & Main effects & $\boldsymbol{F}$ & $P$-value \\
\hline \multirow[t]{3}{*}{ General activity (9A) } & 1 & $2.543(3)$ & 0.067 \\
\hline & 2 & $51.092(9)$ & $<0.001$ \\
\hline & 3 & $1.125(27)$ & 0.305 \\
\hline \multirow[t]{3}{*}{ Mood (9B) } & 1 & $1.266(3)$ & 0.296 \\
\hline & 2 & $28.290(9)$ & $<0.001$ \\
\hline & 3 & $\mathrm{I} .408(27)$ & 0.086 \\
\hline \multirow[t]{3}{*}{ The ability to walk (9C) } & I & $3.547(3)$ & 0.021 \\
\hline & 2 & $31.016(9)$ & $<0.001$ \\
\hline & 3 & $1.090(27)$ & 0.347 \\
\hline \multirow[t]{3}{*}{ Normal work (9D) } & I & $3.734(3)$ & 0.017 \\
\hline & 2 & $32.131(9)$ & $<0.001$ \\
\hline & 3 & $1.512(27)$ & 0.049 \\
\hline \multirow[t]{3}{*}{ Relations with other people (9E) } & I & $2.074(3)$ & 0.116 \\
\hline & 2 & $44.375(9)$ & $<0.001$ \\
\hline & 3 & $2.141(27)$ & $<0.001$ \\
\hline \multirow[t]{3}{*}{ Sleep (9F) } & I & $0.419(3)$ & 0.740 \\
\hline & 2 & $20.974(9)$ & $<0.001$ \\
\hline & 3 & $0.705(27)$ & 0.864 \\
\hline \multirow[t]{3}{*}{ Enjoyment of life (9G) } & I & $0.732(3)$ & 0.538 \\
\hline & 2 & $48.190(9)$ & $<\mathbf{0 . 0 0 I}$ \\
\hline & 3 & $2.365(27)$ & $<0.001$ \\
\hline
\end{tabular}

Notes: F: Fisher test, degrees of freedom are given in parentheses. $P$, significance level. Main effects: I, the effect of the drug; 2 , the effect of time; 3 , interactions of I and 2. 9A-9G, item numbers of the questionnaire. Significant values are marked in bold.

The smallest negative effect of pain on normal work was observed during morphine therapy $(P=0.017)$. The effect of pain on work in relation to time of treatment was significant $(P<0.001)$. Interactions of the type and time of treatment with regard to the effect of pain on performing normal work by patients were significant $(P=0.049)$.

The effect of pain on relations with other people, sleep and enjoyment life

Analyzing a negative effect of pain on relations with other people, significant effects with regard to the time of treatment as well as interactions of type and time of treatment were observed $(P<0.001)$. In terms of the effect of pain on sleep, a significant effect occurred $(P<0.001)$ with regard to time of treatment. Analyzing a negative effect of pain on enjoyment of life, significant effects of time of treatment as well as interaction of type and time of treatment were observed $(P<0.001)$

\section{Doses of opioids}

The doses of opioids were adjusted depending on the analgesic effect and adverse effects; for the majority of the patients, the initial dose had to be increased. The range of the doses for the opioids studied was $35-140 \mu \mathrm{g} / \mathrm{h}$ for buprenorphine, 25-100 $\mu \mathrm{g} / \mathrm{h}$ for fentanyl, $10-60 \mathrm{mg} /$ day for oxycodone and $20-80 \mathrm{mg} / \mathrm{day}$ for morphine. Average daily doses of morphine and oxycodone, average hourly doses of fentanyl and buprenorphine with percentile increases compared with initial doses in all patients are shown in Table 7.

Average use of immediate-release morphine administered by oral route in the treatment of breakthrough pain, during 28 days of treatment in all patients, in the group of patients with neuropathic pain and nociceptive pain is shown in Table 8.

\section{Non-opioid analgesics, step 2 opioids, adjuvant analgesics}

Prior to the trial, the patients used the following drugs: 57 patients received tramadol, 52 paracetamol, 30 ketoprofen, 10 metamizol, 3 patients received diclofenac and 3 received dexamethasone, meloxicam and ibuprofen were taken by 2 patients each. On day 28 of the trial, 16 patients took paracetamol, 12 dexamethasone, 4 ketoprofen; gabapentin, carbamazepine and amitriptyline were taken by 2 patients each, ibuprofen and dexketoprofen were taken by 1 patient each.

Table 7 Hourly doses of buprenorphine and fentanyl and mean daily doses of oxycodone and morphine and percentage increase of the average daily doses of opioids studied compared to the initial daily doses, in all patients

\begin{tabular}{|c|c|c|c|c|c|}
\hline Time & Opioid doses & Buprenorphine & Oxycodone & Fentanyl & Morphine \\
\hline Day I & Initial dose & $35 \mu \mathrm{g} / \mathrm{h}$ & 10 mg/day & $25 \mu \mathrm{g} / \mathrm{h}$ & $20 \mathrm{mg} /$ day \\
\hline \multirow[t]{3}{*}{ Day 7} & Range & $35-52 \mu \mathrm{g} / \mathrm{h}$ & $10-40 \mathrm{mg}$ & $25-50 \mu \mathrm{g} / \mathrm{h}$ & $20-40 \mathrm{mg}$ \\
\hline & Mean \pm SD & $43.23 \pm 10.90 \mu \mathrm{g} / \mathrm{h}$ & $19.37 \pm 7.72 \mathrm{mg}$ & $30.12 \pm \mathrm{I} . .44 \mu \mathrm{g} / \mathrm{h}$ & $32.46 \pm 12.22 \mathrm{mg}$ \\
\hline & Dose increase & $23.51 \%$ & $93.70 \%$ & $20.48 \%$ & $63.20 \%$ \\
\hline \multirow[t]{3}{*}{ Day 14} & Range & $35-70 \mu \mathrm{g} / \mathrm{h}$ & $10-40 \mathrm{mg}$ & $25-50 \mu \mathrm{g} / \mathrm{h}$ & $20-60 \mathrm{mg}$ \\
\hline & Mean \pm SD & $54.83 \pm \mathrm{I} I .20 \mu \mathrm{g} / \mathrm{h}$ & $22.58 \pm 7.932 \mathrm{mg}$ & $35.4 \mathrm{I} \pm \mathrm{I} 2.87 \mu \mathrm{g} / \mathrm{h}$ & $40.00 \pm 14.77 \mathrm{mg}$ \\
\hline & Dose increase & $56.65 \%$ & $125.80 \%$ & $41.64 \%$ & $100.00 \%$ \\
\hline \multirow[t]{3}{*}{ Day 21} & Range & $35-105 \mu g / h$ & $20-40 \mathrm{mg}$ & $25-75 \mu \mathrm{g} / \mathrm{h}$ & $20-80 \mathrm{mg}$ \\
\hline & Mean \pm SD & $60.66 \pm 17.33 \mu \mathrm{g} / \mathrm{h}$ & $27.70 \pm 9.81 \mathrm{mg}$ & $42.50 \pm 20.58 \mu \mathrm{g} / \mathrm{h}$ & $51.66 \pm 15.86 \mathrm{mg}$ \\
\hline & Dose increase & $73.31 \%$ & $177.00 \%$ & $70.00 \%$ & $158.30 \%$ \\
\hline \multirow[t]{3}{*}{ Day 28} & Range & $35-140 \mu g / h$ & $20-60 \mathrm{mg}$ & $25-100 \mu g / h$ & $20-80 \mathrm{mg}$ \\
\hline & Mean \pm SD & $63.00 \pm 24.57 \mu \mathrm{g} / \mathrm{h}$ & $31.64 \pm 13.70 \mathrm{mg}$ & $45.00 \pm 25.82 \mu \mathrm{g} / \mathrm{h}$ & $56.66 \pm 11.54 \mathrm{mg}$ \\
\hline & Dose increase & $80.00 \%$ & $216.40 \%$ & $80.00 \%$ & $183.30 \%$ \\
\hline
\end{tabular}


Table 8 The use of immediate-release morphine administered by oral route in milligrams, in the treatment of breakthrough pain in all patients during 28 days, in the group of patients with neuropathic pain and nociceptive pain; mean values and standard deviations are given

\begin{tabular}{lllll}
\hline Patient group & Buprenorphine & Oxycodone & Fentanyl & Morphine \\
\hline All patients $(\mathrm{n}=62)$ & $457.65 \pm 479.47$ & $338.13 \pm 273.94$ & $390.67 \pm 377.48$ & $260.00 \pm 327.04$ \\
Patients with neuropathic pain $(\mathrm{n}=30)$ & $657.50 \pm 552.13$ & $361.25 \pm 287.7$ & $557.14 \pm 360.22$ & $280.00 \pm 409.06$ \\
Patients with nociceptive pain $(\mathrm{n}=32)$ & $280.00 \pm 342.93$ & $315.00 \pm 277.49$ & $280.00 \pm 361.48$ & $240.00 \pm 251.93$ \\
\hline
\end{tabular}

\section{Adverse effects}

Out of 62 patients, 9 did not complete the trial: 5 patients died, 3 patients resigned from participation in the trial: 2 because of adverse events (dizziness, nausea and vomiting, skin lesions), 1 due to lack of consent to complete the research tools, 1 was referred to hospital because of deteriorated general health status (Figure 2).

In the group of 30 patients with neuropathic pain, $26(86.67 \%)$ patients completed the treatment lasting 28 days; 3 (10\%) patients died and $1(3.33 \%)$ patient receiving morphine decided to discontinue the therapy on day 7 of the trial due to its adverse effects: dizziness, nausea and vomiting. In the group of 32 patients with nociceptive pain, $27(84.37 \%)$ patients completed the trial; 2 (6.25\%) patients died, $2(6.25 \%)$ patients resigned from participating in the trial (1 patient treated with fentanyl due to lack of consent to complete the research tools, 1 patient treated with buprenorphine on day 12 of the trial due to adverse effects: skin lesions, malaise, nausea and vomiting), 1 (3.13\%) patient treated with fentanyl on day 12 of the trial was referred to hospital due to disorders of consciousness. ESAS and BFI were used to assess adverse events.

\section{Edmonton symptom assessment system}

According to ESAS, there were no changes in constipation, vomiting and dyspnea.

\section{Drowsiness}

The severity of drowsiness has changed in relation to treatment time $(P=0.009)$. An increase in the severity of

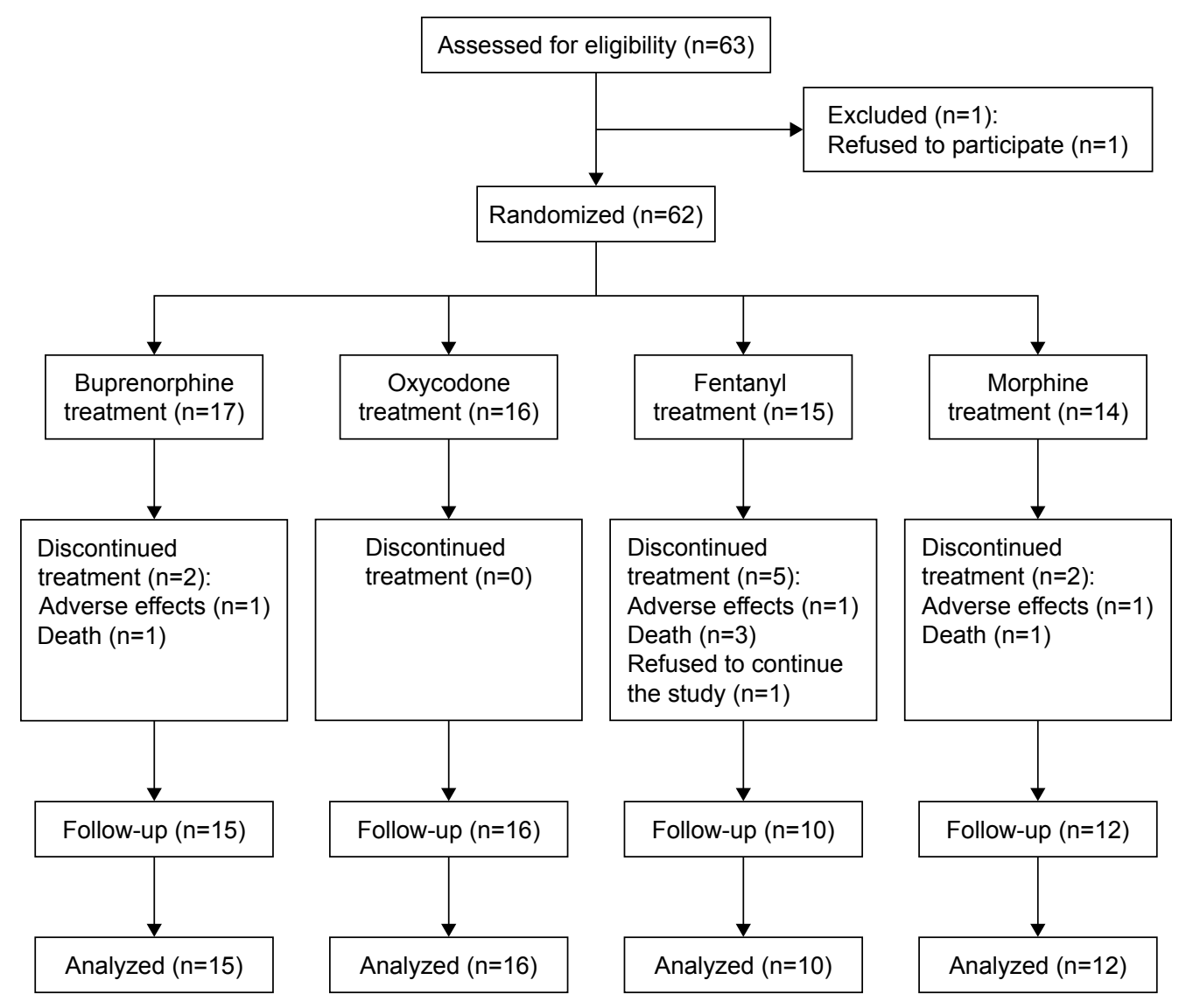

Figure 2 Flowchart of the study. 
drowsiness was found during the first 9 days of therapy and a gradual decrease in the symptom severity was observed on the following days of the trial.

\section{Nausea and appetite}

The severity of nausea changed in relation to treatment time $(P<0.001)$. An increase in the severity of nausea was found during the first 9 days of treatment and a gradual symptom resolution on the following days of the trial. Loss of appetite changed in relation to time of the treatment $(P<0.001)$. A gradual improvement in appetite was found during therapy.

\section{Depression, anxiety, tiredness and well-being}

The level of depression changed in relation to treatment time $(P<0.001)$. A gradual reduction in the severity of depression was found on the following days of the trial. The effect of treatment time was observed with regard to anxiety, fatigue and well-being $(P<0.001)$; for the well-being, there was also a significant effect of interaction of type of treatment and treatment time $(P=0.001)$. There was a gradual reduction in the anxiety level and severity of tiredness as well as improvement of well-being during the therapy.

\section{The Bowel Function Index}

The assessment of severity of constipation was made using the BFI. In terms of constipation assessed by BFI, no significant changes in the symptom severity were found during the treatment with respect to all the ANOVA effects studied. Moreover, the mean scores of BFI in all measurements for all 4 opioids were within normal range.

\section{Discussion}

A randomized, multi-center, parallel-group clinical trial aimed to compare the analgesic effect and adverse effects of patients remaining under care of the Home Hospice or Palliative Outpatient Clinic who were diagnosed with cancer and who, due to severe pain (6-10 by NRS), required the use of opioid analgesics. For the purpose of pain treatment, one of the 4 opioids was used: morphine or oxycodone in the form of controlled-release tablets administered orally or fentanyl or buprenorphine administered transdermally.

\section{Analgesic effects}

Buprenorphine, oxycodone, fentanyl and morphine both in patients with neuropathic as well as nociceptive pain were effective analgesics, which was expressed by the reduction in the mean value of the baseline severity of pain in NRS (statistically significant differences) with respect to pain at its worst, pain at its least, pain on the average and pain right now assessed by BPI-SF. Similar effects of statistically significant reduction in the initial severity of pain were also seen in ESAS and EORTC QLQ-C15-PAL pain assessment scales (data not shown).

No statistically significant differences were proved in terms of reduction in pain between the groups of patients with neuropathic and nociceptive pain. This is probably due to the fact that most patients experienced pain that was mixed in character, with nociceptive and neuropathic pain component (71\% patients experienced at least 2 types of pain), and they qualified for the type of pain subgroup on the basis of the prevailing type of pain. In the conducted trial, patients with predominantly neuropathic pain required higher doses of morphine in the treatment of breakthrough pain in comparison with patients with nociceptive pain. This applied to all the opioids studied. Additionally, the requirement for morphine to treat breakthrough pain during the treatment with opioids administered transdermally (fentanyl and buprenorphine) was twice as high as during the treatment with opioids administered orally, which indirectly suggests the higher efficacy of morphine and oxycodone in the treatment of neuropathic pain. More patients with neuropathic pain required the use of adjuvant analgesics (dexamethasone, antiepileptic and/or antidepressant) and paracetamol, which confirmed that pain with the neuropathic component was more difficult to treat.

No statistically significant differences were proved in the severity of pain in patients treated with slow-release oral morphine and oxycodone in comparison with those treated with fentanyl and buprenorphine used transdermally. ${ }^{19-21}$ During the trial, no statistically significant differences were found in terms of degree and speed of onset of analgesic effect for particular opioids, although in case of using buprenorphine, there was a tendency to achieve complete analgesia later, which resulted from its pharmacokinetic and pharmacodynamic properties. $^{22}$

Regarding the time which elapses from the beginning of the therapy with the studied opioids to the moment effective analgesia is obtained, it was seen that all 4 drugs caused a significant reduction in the initial severity of pain measured by means of NRS, with the effect observed mainly during the first 14 days of the therapy, which correlated with substantial improvement of the overall QoL (data not shown) during this period of therapy. The analgesic effect of the studied opioids in the subsequent 14 days of the therapy remained on a more stable level. Although the first analgesic effects of opioids can be seen shortly after the drug is administered (minutes, hours), a period of 14 days may be regarded as the time which 
is necessary for the adequate assessment of the full opioid analgesic effect, both in the clinical trials and in everyday practice of pain treatment in cancer patients.

Limited number of clinical trials compared all the 4 opioids studied. In the open randomized clinical trial conducted on 108 cancer patients, who did not respond to weak opioids therapy, slow-release morphine (initial dose of $60 \mathrm{mg} /$ day) and methadone (initial dose $15 \mathrm{mg} /$ day) were administered by oral route and fentanyl (initial dose $25 \mu \mathrm{g} / \mathrm{h}$ ) was administered transdermally for 28 days. A comparable analgesic efficacy as well adverse effects and patients' QoL were observed during the treatment with the opioids studied. ${ }^{23}$ In a study conducted in Italy, analgesia, adverse effects and QoL during treatment with morphine and oxycodone administered orally with buprenorphine and fentanyl administered transdermally were compared. ${ }^{7}$ However, the trial opioids were compared indirectly, by studying observations in the course of the treatment with particular drugs, without randomization, with patients receiving a given opioid at the doctor's discretion (the trial was observational in character). A newer and large Italian clinical study comprising over 520 patients showed similar effectiveness and tolerance regarding adverse effects of the 4 opioids studied. ${ }^{8}$ The results of all these studies are in line with the scores obtained in our study.

Over the course of treatment, an increase in average daily opioid doses was seen, which became clear in the light of the fact that the treatment was commenced with low doses, which were gradually increased to obtain appropriate analgesia and acceptable adverse effects (titration). Of note, a similar percentile increase in doses occurred for buprenorphine and fentanyl as well as for oxycodone and morphine. A significantly higher percentile increase in the doses of oxycodone and morphine resulted from lower initial equivalent doses in comparison with buprenorphine and fentanyl. It should be noted that there were similar proportions of the average doses of buprenorphine and fentanyl, which indicates an accurate choice and probably equivalent analgesic effect of $35 \mu \mathrm{g}$ dose of buprenorphine and $25 \mu \mathrm{g}$ dose of fentanyl. In case of oxycodone and morphine administered orally, the equivalent doses ratio within the proportion of $1: 1.5$ and $1: 2$, although a smaller negative effect of pain on walking ability and normal work (BPI-SF) as well as a greater improvement in the physical function of patients (EORTC QLQ-C15-PAL, data not shown) were seen during morphine therapy.

\section{Adverse effects}

The adverse effects seen in the patients during the trial were, as a rule, characterized by small severity, but for 3 patients, they were the reason to discontinue the trial. When the opioid doses are adjusted correctly to the severity of pain (titration), serious adverse effects occur extremely rarely. Most adverse effects are usually transient, except for opioid-induced bowel dysfunction, particularly constipation, which occurs throughout the course of the opioid therapy.

The most common adverse effects occurring in the patients undergoing treatment included nausea and drowsiness. At the beginning of the trial, nausea was observed in 15 patients: in 11 patients, its severity was small; in 4 of them, nausea was severe. The severity of nausea increased over the first 7 days of treatment; during the following 14 days, it remained on much the same level; and in the last week of the trial, it decreased (the effect of treatment time in EORTC QLQ-C15-PAL and ESAS).

No significant differences were found between the 4 opioids in the severity of nausea, but there was a tendency for a greater severity of nausea in patients treated with morphine. According to the trial protocol, patients did not receive antiemetics when a particular opioid was started. Currently, EAPC does not recommend prophylactic antiemetic management when the opioid therapy is commenced ${ }^{5}$ moreover, experts of the Multinational Association of Supportive Care in Cancer and ESMO were unable to render any recommendations on the management of opioid-induced nausea and vomiting. ${ }^{24}$ However, antiemetics may be recommended at the beginning of the opioid therapy in patients with risk factors. In order to resolve controversies about the mandatory introduction of antiemetics when the opioid therapy is commenced, further controlled clinical trials are required.

In case of vomiting and constipation, no significant differences were found. Out of the patients participating in the trial, only 8 patients showed no symptoms connected with constipation, and in all the remaining patients, the symptoms differed in severity. Considering BFI scores on day 28, 15 (24\%) patients suffered from constipation (mean BFI score over 3$)$, while for 11 (17.74\%) patients, BFI scores on day 28 were higher, when compared with those from the beginning of the trial. However, no mean values $>3$ were found in the assessment of the severity of constipation conducted in all patients, either for any of the particular 3 items or mean BFI scores. This proves the efficacy of constipation prophylaxis, which is further confirmed by the fact that the severity of constipation did not increase during the trial, according to BFI, ESAS and EORTC QLQ-C15-PAL. According to the guidelines of International Expert Panel, all patients received, as prophylaxis, lactulose at the dose of $10 \mathrm{~mL}$ twice daily and an adequate fluid provision. ${ }^{14}$ One of the factors which could have contributed to the effective prophylaxis was a relatively good general health status of the patients 
(mean Karnofsky value over 60, data not shown), thanks to which the patients could perform physical activity as recommended, at the level that was adjusted to individual possibilities of particular patients.

Drowsiness, in much the same way as nausea, increased gradually over the first 14 days of the trial, and then gradually decreased (ESAS time effect). Patients $>70$ years of age are more at risk of developing disorders of consciousness associated with the use of opioids, which results from the occurrence of comorbidities, particularly kidney and liver dysfunction, which may exacerbate the adverse effects caused by opioids, for example, due to accumulation of morphine metabolites. Patients with impaired renal or hepatic function were not enrolled onto the trial. Patients' average age was the lowest in the group of patients receiving morphine (62 years of age), and the highest in the group of patients treated with oxycodone ( $>72$ years of age). The results of the present study concerning the severity of drowsiness are congruent with the state-of-the-art knowledge about the adverse effects of opioids. ${ }^{25}$

With respect to loss of appetite assessed by ESAS and EORTC QLQ-C15-PAL (data not shown), the effect of time was observed. The improvement in appetite occurred mainly in the first 14 days of treatment, which may be associated with the analgesic effect that also showed a similar tendency. This could beneficially influence the patients' QoL, which was confirmed by the improvement in overall QoL, also observed during the first 14 days of treatment. The trial did not include the assessment of dry mouth (xerostomia), which could also influence the level of appetite. No differences were found in dyspnea, although 14 (22.58\%) patients participating were diagnosed with lung cancer, because the severity of dyspnea in the trial patients was small.

\section{Strengths and limitations of the study}

Strengths of the trial include the comparison of 4 opioids in terms of analgesia, adverse effects and QoL, randomization, a multicenter design, a long monitoring period and use of several methods for assessment of pain, other symptoms and QoL. The compatibility of results yielded by various research tools indicates their accuracy, reliability, sensitivity to change, and usefulness in the clinical practice and for monitoring of symptomatic treatment of cancer patients.

A serious limitation to the trial is the small number of patients enrolled due to substantial difficulties with patient enrollment connected with, among others, the pre-condition of not having been treated with strong opioids, the use of which is now common practice in cancer patients with severe pain. Other limitations include no blind trial and placebo use, which may, however, be explained by significant inconvenience for the patients connected with the necessity of taking a drug or placebo both orally and transdermally as well as ethical doubts associated with administering placebo to cancer patients with severe pain.

\section{Conclusion}

In the treatment of severe pain in cancer patients, buprenorphine, oxycodone, fentanyl and morphine show similar analgesic efficacy, with the full analgesic effect being achieved gradually, mainly during the first 14 days of treatment. In comparison with buprenorphine, oxycodone and fentanyl, during the morphine therapy, a smaller negative effect of pain on walking ability and work was observed; there was a smaller use of rescue morphine administered in the treatment of breakthrough pain. The trial opioids showed a similar profile and the severity of adverse effects. The prophylaxis of laxatives prevented opioid-induced constipation. At the beginning of the opioid therapy, prophylactic use of antiemetics may be considered in order to avoid nausea.

\section{Acknowledgments}

We acknowledge all colleagues participating in the study: Dr Jacek Januszczyk, Dr Kordian Waroński, Dr Sebastian Werner, and Dr Marek Widenka.

\section{Disclosure}

The authors report no conflicts of interest in this work.

\section{References}

1. World Health Organization. Cancer Pain Relief. World Health Organization, Geneva; 1986.

2. Bandieri E, Romero M, Ripamonti CI, et al. Randomized trial of low-dose morphine versus weak opioids in moderate cancer pain. J Clin Oncol. 2016;34(5):426-442.

3. Ripamonti CI, Campa T, Fagnoni E, et al; on behalf of MERITO Study Group. Normal-release oral morphine starting dose in cancer patients with pain. Clin J Pain. 2009;25(5):386-390.

4. Leppert W, Krajnik M, Wordliczek J. Delivery systems of opioid analgesics for pain relief: a review. Curr Pharm Des. 2013;19(41): 7271-7293.

5. Caraceni A, Hanks G, Kaasa S, et al; European Palliative Care Research Collaborative (EPCRC), on behalf of the European Association for Palliative Care (EAPC). Use of opioid analgesics in the treatment of cancer pain: evidence-based recommendations from the EAPC. Lancet Oncol. 2012;13(2):e58-e68.

6. Ripamonti CI, Santini D, Maranzano E, Berti M, Roila F; ESMO Guidelines Working Group. Management of cancer pain: ESMO clinical practice guidelines. Ann Oncol. 2012;23(Suppl 7):vii, 139-154.

7. Corli O, Montanari M, Deandrea S, Greco MT, Villani W, Apolone G. An exploratory analysis on the effectiveness of four strong opioids in patients with cancer pain. Pain Med. 2012;13(7):897-907. 
8. Corli O, Floriani I, Roberto A, et al; on behalf of the CERP STUDY OF PAIN GROUP. Are strong opioids equally effective and safe in the treatment of chronic cancer pain? A multicentre randomized phase IV 'real life' trial on the variability of response to opioids. Ann Oncol. 2016;27(6):1107-1115.

9. Mystakidou K, Tsilika E, Parpa E, Galanos A, Vlahos L. Brief cognitive assessment of cancer patients: evaluation of the mini-mental state examination (MMSE) psychometric properties. Psychooncology. 2007; 16(4):352-357.

10. Cleeland CS, Ryan KM. Pain assessment: global use of the brief pain inventory. Ann Acad Med Singapore. 1994;23(2):129-138.

11. Majkowicz M, Czuszyńska Z, Leppert W, Maszkowska-Kopij K. Praktyczne wykorzystanie skali ESAS (Edmonton Symptom Assessment System) w opiece paliatywnej [Practical application of ESAS (Edmonton Symptom Assessment System) in palliative care]. Nowotwory. 1998;48:847-857. Polish.

12. Groenvold M, Petersen MA, Aaronson NK, et al; EORTC Quality of Life Group. The development of the EORTC QLQ-C15-PAL: a shortened questionnaire for cancer patients in palliative care. Eur $J$ Cancer. 2006;42(1):55-64.

13. Rentz AM, Yu R, Müller-Lissner S, Leyendecker P. Validation of the Bowel Function Index to detect clinically meaningful changes in opioid-induced constipation. J Med Econ. 2009;12(4):371-383.

14. Argoff CE, Brennan MJ, Camilleri M, et al. Consensus recommendations on initiating prescription therapies for opioid-induced constipation Pain Med. 2015;16(12):2324-2337.

15. Zigmond AS, Snaith RP. The hospital anxiety and depression scale. Acta Psychiatr Scand. 1983;67(6):361-370.

16. Bjelland I, Dahl AA, Haug TT, Neckelmann D. The validity of the hospital anxiety and depression scale. An updated literature review. J Psychosom Res. 2002;52(2):69-77.
17. Karnofsky DA, Burchenal JH. The clinical evaluation of chemotherapeutic agents in cancer. In: MacLeod CM, editor. Evaluation of Chemotherapeutic Agents. New York, NY: Columbia University Press; 1949:196.

18. Mor V, Laliberte L, Morris JN, Wiemann M. The Karnofsky performance status scale. An examination of its reliability and validity in a research setting. Cancer. 1984;53(9):2002-2007.

19. Przeklasa-Muszyńska A, Dobrogowski J. Transdermal buprenorphine for the treatment of moderate to severe chronic pain: results from a large multicenter, non-interventional post-marketing study in Poland. Curr Med Res Opin. 2011;27(6):1109-1117.

20. Likar R, Sittl R. Transdermal buprenorphine for treating nociceptive and neuropathic pain: four case studies. Anesth Analg. 2005;100(3): 781-785.

21. Pergolizzi JV, Mercadante S, Echaburu AV, et al. The role of transdermal buprenorphine in the treatment of cancer pain: an expert panel consensus. Curr Med Res Opin. 2009;25(6):1517-1528.

22. Lutfy K, Cowan A. Buprenorphine: a unique drug with complex pharmacology. Curr Neuropharmacol. 2004;2(4):395-402.

23. Mercadante S, Porzio G, Ferrera P, et al. Sustained-release oral morphine versus transdermal fentanyl and oral methadone in cancer pain management. Eur J Pain. 2008;12(8):1040-1046.

24. Roila F, Malassiotis A, Herrstetd J, et al. 2016 MASCC and ESMO guideline update for the prevention of chemotherapy - and radiotherapyinduced nausea and vomiting and of nausea and vomiting in advanced cancer patients. Ann Oncol. 2016;27(Suppl 5):119-133.

25. Bennett M. Treatment of cancer pain. In: Tracey I, editor. Pain 2012. Refresher courses 14th World Congress on Pain. Seattle, WA: IASP Press; 2012:301-316.
Drug Design, Development and Therapy

\section{Publish your work in this journal}

Drug Design, Development and Therapy is an international, peerreviewed open-access journal that spans the spectrum of drug design and development through to clinical applications. Clinical outcomes, patient safety, and programs for the development and effective, safe, and sustained use of medicines are the features of the journal, which

\section{Dovepress}

has also been accepted for indexing on PubMed Central. The manuscript management system is completely online and includes a very quick and fair peer-review system, which is all easy to use. Visit http://www.dovepress.com/testimonials.php to read real quotes from published authors.

Submit your manuscript here: http://www.dovepress.com/drug-design-development-and-therapy-journal 